Check for updates

Cite this: RSC Adv., 2017, 7, 22818

\title{
Ultrathin Co-Fe hydroxide nanosheet arrays for improved oxygen evolution during water splitting $\dagger$
}

Received 27th January 2017

Accepted 10th April 2017

DOI: 10.1039/c7ra01202k

rsc.li/rsc-advances

\author{
Tingting Zhou, ${ }^{\mathrm{ab}}$ Zhen Cao, ${ }^{\mathrm{a}}$ Heng Wang, ${ }^{\mathrm{a}}$ Zhen Gao, ${ }^{\mathrm{a}}$ Long $\mathrm{Li}^{\mathrm{a}}{ }^{\mathrm{a}}$ Houyi Ma ${ }^{\mathrm{b}}$ \\ and Yunfeng Zhao (D)*a
}

The Fe-doping of hierarchical Co hydroxide nanosheet arrays $\left(\mathrm{Co}_{y} \mathrm{Fe}_{1-y}(\mathrm{OH})_{x} \mathrm{NSAs}\right)$ integrated on a threedimensional electrode is shown to contribute to both increasing the available surface area and number of active sites. Ultrathin secondary nanosheets with different Co to Fe ratios that are subsequently grown on these primary nanoarrays are found to exhibit high oxygen evolution reaction (OER) activity. The optimal composition of $\mathrm{Co}_{y} \mathrm{Fe}_{1-y}(\mathrm{OH})_{x}$ NSAs turns out to be $\mathrm{Co}_{0.7} \mathrm{Fe}_{0.3}(\mathrm{OH})_{x}$ NSAs, which allows for an OER onset overpotential as low as $220 \mathrm{mV}$ and a small Tafel slope at $62.4 \mathrm{mV} \mathrm{dec}{ }^{-1}$, while also providing excellent long-term durability $(>100 \mathrm{~h})$ and a high turnover frequency (TOF) of $0.172 \mathrm{~s}^{-1}$ at an overpotential of $380 \mathrm{mV}$. The specific activity of Fe-doped $\mathrm{Co}_{0.7} \mathrm{Fe}_{0.3}(\mathrm{OH})_{x} \mathrm{NSAs}$ at an overpotential of $350 \mathrm{mV}\left(0.37 \mathrm{~mA} \mathrm{~cm}_{\mathrm{BET}}{ }^{-2}\right)$ is also twice as high as that of undoped $\mathrm{Co}(\mathrm{OH})_{2} \mathrm{NSAs}$.

\section{Introduction}

The excessive consumption of fossil fuels and the increasingly serious environmental concerns associated with this have stimulated intense research into alternative energy conversion and storage systems that can provide high efficiency, environmental safety and economic feasibility. ${ }^{1-4}$ The electrochemical splitting of water into $\mathrm{O}_{2}$ and $\mathrm{H}_{2}$ is widely accepted as one of the most promising technologies for producing fuel from a renewable and abundant source (i.e., water), but the kinetically slow oxygen evolution reaction (OER) restricts the overall reaction., ${ }^{5,6}$ This has led in recent years to considerable interest in electrocatalysts capable of promoting the OER process, with $\mathrm{RuO}_{2}$ and $\mathrm{IrO}_{2}$ being found to provide excellent performance. ${ }^{7}$ Their practical application, however, has been limited by the high price of these scarce elements.

More recently, first-row transition metal compounds ${ }^{8,9}$ have been investigated as more abundant and economical OER catalysts, with hydroxides receiving particular attention due to their excellent OER performance. ${ }^{10-13}$ Of these, there are a number of Co-based ${ }^{14-16}$ and Ni-based ${ }^{17,18}$ catalysts work as attractive alternative for OER thanks to their relative abundance, low cost and competitive OER activity. Their catalytic performance can be further improved by modulating their $3 \mathrm{~d}$ orbital electron state through heterogeneous doping to create

${ }^{a}$ Tianjin Key Laboratory of Advanced Functional Porous Materials, Institute for New Energy Materials and Low-Carbon Technologies, Tianjin University of Technology, Tianjin 300384, China. E-mail: yfzhao@tjut.edu.cn

${ }^{b}$ School of Chemistry and Chemical Engineering, Shandong University, Jinan 250100, China

$\dagger$ Electronic supplementary information (ESI) available. See DOI: $10.1039 / \mathrm{c} 7 \mathrm{ra0} 01202 \mathrm{k}$ more active sites and greater electrical conductivity. ${ }^{19}$ For example, Fe-doping has been found to improve the water oxidation activity of both Ni-based ${ }^{20-23}$ and Co-based ${ }^{24,25}$ catalysts. A well-known example of $\mathrm{Co}-\mathrm{Fe}$ as an OER catalyst was CoFe-layered double hydroxide (LDH), ${ }^{26}$ which exhibited higher OER activity than CoNi-LDH. Qiu et al. propose that Fe-doping provide enlarged LDH interlayer space, which is beneficial to the absorption of $\mathrm{OH}^{-},{ }^{27}$ while other researchers have suggested that the addition of $\mathrm{Fe}$ in $\mathrm{Co}_{1-x} \mathrm{Fe}_{x}(\mathrm{OOH})$ films provides more active sites. ${ }^{28} \mathrm{~A}$ more recent study by Feng $e t$ al. suggested that the $\mathrm{FeOOH}$ on $\mathrm{FeOOH} / \mathrm{Co} / \mathrm{FeOOH}$ nanotube host can significantly lower the energy barrier of products and intermediates, thereby promoting catalytic reactions ${ }^{29}$ However, the addition of heterogeneous ions can also efficiently increase the geometric roughness. ${ }^{30,31}$ Furthermore, in ensuring the electrocatalytic performance of these powder nanomaterials, various additives are often used to enhance their conductivity and filmforming ability. ${ }^{32}$ Addition of polymers or the aggregation of catalyst particles bring about a deteriorate electrode performance, making the direct construction of a hierarchically structured and high-performance nanocatalysts a more attractive approach. ${ }^{33,34}$

In this work, we present a unique Co-Fe hydroxide nanosheet arrays $\left(\mathrm{Co}_{y} \mathrm{Fe}_{1-y}(\mathrm{OH})_{x}\right.$ NSAs $)$ supported on $\mathrm{Cu}$ foam electrode that exhibits high OER performance due to optimization of both its intrinsic activity and geometric roughness. The low Tafel slope and $R_{\mathrm{ct}}$ of $\mathrm{Co}_{0.70} \mathrm{Fe}_{0.30}(\mathrm{OH})_{x}$ NSAs indicate an improved charge transfer kinetic, indicating doping of $\mathrm{Fe}$ is a sufficient solution to eliminate the kinetically slow of OER. The specific activity of $\mathrm{Co}_{0.7} \mathrm{Fe}_{0.3}(\mathrm{OH})_{x}$ NSAs at an overpotential of $350 \mathrm{mV}\left(0.37 \mathrm{~mA} \mathrm{~cm}{ }_{\mathrm{BET}}{ }^{-2}\right)$ is twice as high as that of undoped $\mathrm{Co}(\mathrm{OH})_{2} \mathrm{NSAs}$, further prove the positive effect of Fe doping on 
OER activity. The $\mathrm{Cu}$ foam plays a role as both electron collector and source to grow the $\mathrm{Cu}_{2} \mathrm{O}$ nanoarrays that serve as a sacrificial template to guide the formation of the Co-Fe hydroxide nanosheets. Those self-supported electrodes possess good conductivity and sturdiness structure, bring about excellent stability, with no obvious decline in current density after $100 \mathrm{~h}$. This three-dimensional hierarchically porous electrode design offer the advantages of low working potential, large current density, high turnover frequency (TOF) and good durability.

\section{Results and discussion}

To provide a sacrificial template to induce the growth of $\mathrm{Co}_{y^{-}}$ $\mathrm{Fe}_{1-y}(\mathrm{OH})_{x}$ NSAs, $\mathrm{Cu}_{2} \mathrm{O}$ nanoarrays were first produced on $\mathrm{Cu}$ foam by a simple anodic oxidation route. ${ }^{35}$ As shown in Fig. 1a, the $\mathrm{Co}_{y} \mathrm{Fe}_{1-y}(\mathrm{OH})_{x}$ NSAs were then fabricated by a solutionphase cation exchange method at room temperature by simply dipping the $\mathrm{Cu}$ foam loaded with $\mathrm{Cu}_{2} \mathrm{O}$ nanoarrays into a aqueous solution of $\mathrm{CoCl}_{2}$ and $\mathrm{FeCl}_{2} \cdot{ }^{36}$ During the cation exchange process, the $\mathrm{Cu}_{2} \mathrm{O}$ nanowires were etched by $\mathrm{S}_{2} \mathrm{O}_{3}{ }^{2-}$, releasing $\mathrm{OH}^{-}$. Then the $\mathrm{Co}_{y} \mathrm{Fe}_{1-y}(\mathrm{OH})_{x}$ NSAs precipitated, and these new $\mathrm{Co}_{y} \mathrm{Fe}_{1-y}(\mathrm{OH})_{x}$ NSAs structures inherited the geometry of the $\mathrm{Cu}_{2} \mathrm{O}$ template. Secondary $\mathrm{Co}_{y} \mathrm{Fe}_{1-y}(\mathrm{OH})_{x}$ NSAs nanostructures formed depending on the solubility of the products and the $\mathrm{pH}$ of the reaction system. Therefore, we can regulate the surface area of $\mathrm{Co}_{y} \mathrm{Fe}_{1-y}(\mathrm{OH})_{x}$ NSAs by change the ratio of Co-Fe. As shown in Fig. S1a, $\dagger$ the initial $\mathrm{Cu}$ foam had a $3 \mathrm{D}$ skeleton structure with a smooth microscopic surface, $\mathrm{Cu}_{2} \mathrm{O}$ nanoarrays with a mean diameter of $30 \mathrm{~nm}$ were observed on its surface after anodic oxidation (Fig. 1b). The XRD pattern obtained from the $\mathrm{Cu}_{2} \mathrm{O}$ nanowires (Fig. $\mathrm{S} 4 \dagger$ ) exhibited distinct diffraction peaks that indexed well to $\mathrm{Cu}_{2} \mathrm{O}$ and $\mathrm{Cu}$ phases.

In Fig. $1 \mathrm{c}$ and $\mathrm{S} 1 \mathrm{~b}-\mathrm{f}, \dagger$ we see that the $\mathrm{Co}_{y} \mathrm{Fe}_{1-y}(\mathrm{OH})_{x}$ NSAs inherit the morphology of the $\mathrm{Cu}_{2} \mathrm{O}$ arrays, and so align well on the surface of the $\mathrm{Cu}$ foam. The average diameter of these $\mathrm{Co}(\mathrm{OH})_{2}$ NSAs were estimated to be $\sim 100 \mathrm{~nm}$. A number of secondary nanosheets grow perpendicularly to form cross-like

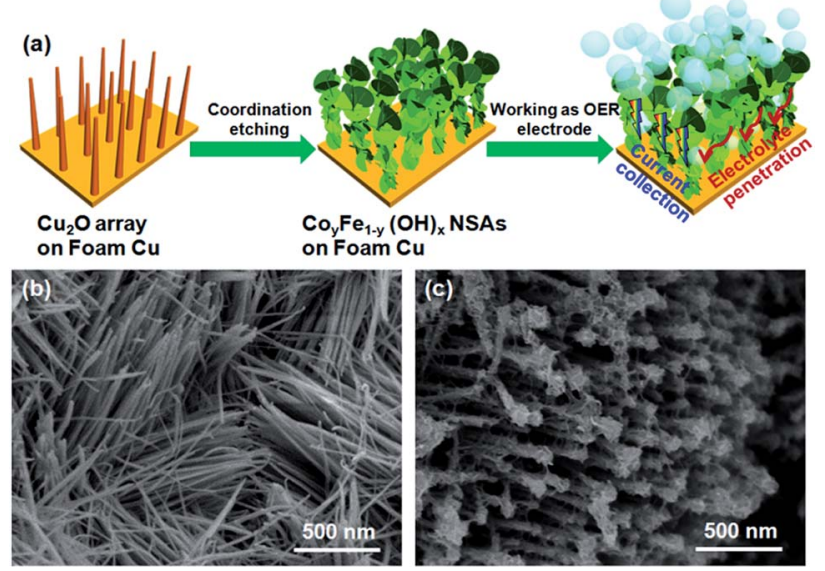

Fig. 1 (a) Schematic illustration of fabrication process of the $\mathrm{Co}_{y^{-}}$ $\mathrm{Fe}_{1-y}(\mathrm{OH})_{x} \mathrm{NSAs}$; (b) SEM image of the $\mathrm{Cu}_{2} \mathrm{O}$ nanoarrays; (c) SEM image of the $\mathrm{CO}_{0.70} \mathrm{Fe}_{0.30}(\mathrm{OH})_{x} \mathrm{NSAs}$. nanosheets that attenuate after $\mathrm{Fe}$ doping, resulting a dramatic change in the morphology of the nanoarrays into something with a mace-like appearance and fluffy surface. These structural characteristics are convenient for the expose of active sites, which should bring about an improvement in catalytic performance. Changing the Co to Fe ratio from 75/25 to $70 / 30$ and 55/45 caused a slight increase in the diameter of the $\mathrm{Co}_{y} \mathrm{Fe}_{1-y}(\mathrm{OH})_{x}$ NSAs, but only within a narrow range of 100$200 \mathrm{~nm}$. Interestingly, the top portion of the $\mathrm{Co}_{0.41} \mathrm{Fe}_{0.59}(\mathrm{OH})_{x}$ and $\mathrm{Fe}(\mathrm{OH})_{x}$ NSAs increased more dramatically in diameter and transformed into a dendritic morphology.

Selected-area electron diffraction (SAED) patterns were employed to investigate the crystal structure of the $\mathrm{Co}_{y} \mathrm{Fe}_{1-y}$ $(\mathrm{OH})_{x}$ NSAs catalysts. The SAED patterns of single metal hydroxides were found to exhibit characteristic traits of a blurry hexagonal matrix (inset of Fig. $2 \mathrm{a}$ and $\mathrm{S} 2 \mathrm{~d} \dagger$ ), indicating a predominantly crystal structure. Only blurred rings were observed in the SAED patterns of change to a predominantly amorphous structure. Amorphous hybrid metal hydroxides (inset of Fig. $2 \mathrm{~b} \& \mathrm{~S} 2 \mathrm{a}-\mathrm{c} \dagger$ ), indicating materials with the great number of under-coordinated metal atoms provide more reactive sites at the catalyst surface, thus facilitating adsorb of bindings, like hydroxyl for OER. ${ }^{17,37}$ The high-resolution TEM (HRTEM) image of $\mathrm{Co}_{0.70} \mathrm{Fe}_{0.30}(\mathrm{OH})_{x}$ NSAs in Fig. 2d lacks discernible lattice fringe, further confirms the amorphous structure. The ultrathin $(\sim 3 \mathrm{~nm})$ nature of the $\mathrm{Co}_{0.70} \mathrm{Fe}_{0.30}(\mathrm{OH})_{x}$ NSAs can also be clearly observed from Fig. $2 d$ and $512 . \dagger$ The XRD patterns of the $\mathrm{Co}_{y} \mathrm{Fe}_{1-y}(\mathrm{OH})_{x}$ NSAs indicates the presence of $\mathrm{Cu}$ and a small amount of $\mathrm{Cu}_{2} \mathrm{O}$ (Fig. S4 $\dagger$ ). The two faint peaks in $17^{\circ}$ and $23^{\circ}$ for $\mathrm{Co}_{y} \mathrm{Fe}_{1-y}(\mathrm{OH})_{x}$ NSAs $(y>0)$ can be indexed Co layer double hydroxide $(\mathrm{Co} \mathrm{LDH}),{ }^{38,39}$ and the faint peaks suggests a predominantly amorphous structure.
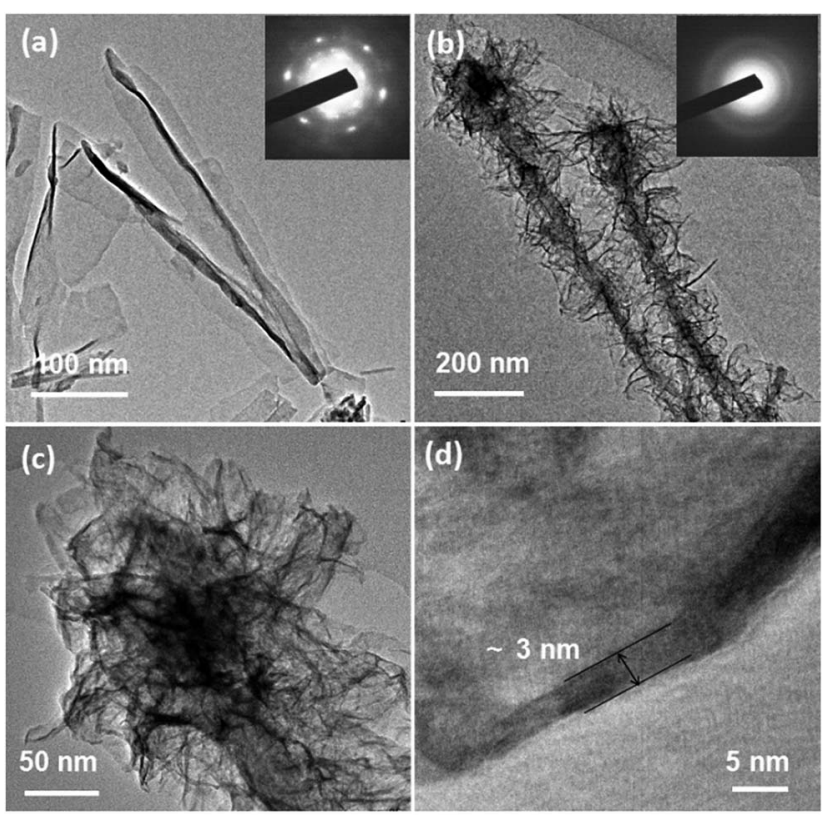

Fig. 2 Low-magnification TEM images and SAED patterns (inset) of (a) $\mathrm{Co}(\mathrm{OH})_{2}$ and (b) $\mathrm{CO}_{0.70} \mathrm{Fe}_{0.30}(\mathrm{OH})_{x} \mathrm{NSAs}$; high-magnification (c) and high resolution (d) TEM images of $\mathrm{CO}_{0.70} \mathrm{Fe}_{0.30}(\mathrm{OH})_{x} \mathrm{NSAs}$. 
Additionally, there was no peak in $17^{\circ}$ and $23^{\circ}$ for $\mathrm{Fe}_{2} \mathrm{O}_{3}$ NSAs. It should be noted that the amorphous nature of the $\mathrm{Co}(\mathrm{OH})_{2}$ NSAs observed by XRD did not conflict with the crystal structures obtained from HRTEM, because the faint crystal lattice the $\mathrm{Co}(\mathrm{OH})_{2}$ NSAs indicated a low crystallinity. ${ }^{36,38}$ The reduction in strength of the $\mathrm{Cu}_{2} \mathrm{O}$ peak compared to the XRD pattern for the $\mathrm{Cu}_{2} \mathrm{O}$ nanoarray indicates a scarcity of $\mathrm{Cu}_{2} \mathrm{O}$ phase in the $\mathrm{Co}_{y} \mathrm{Fe}_{1-y}(\mathrm{OH})_{x}$ NSAs.

The genuine atomic ratios of Co to $\mathrm{Fe}$ in the $\mathrm{Co}_{y} \mathrm{Fe}_{1-y}(\mathrm{OH})_{x}$ NSAs obtained by ICP were found to be roughly analogous to the reactant ratios (Table $\mathrm{S} 1 \dagger$ ), from which the specific value of $y$ in $\mathrm{Co}_{y} \mathrm{Fe}_{1-y}(\mathrm{OH})_{x}$ was determined. The EDS mapping images of $\mathrm{Co}_{0.70} \mathrm{Fe}_{0.30}(\mathrm{OH})_{x}$ NSAs in Fig. S3† show that $\mathrm{Co}, \mathrm{Fe}$ and $\mathrm{Cu}$ were uniformly distributed in the nanostructure. The XPS results for the chemical state of $\mathrm{Co}, \mathrm{Fe}$ and $\mathrm{O}$ species in the as-prepared $\mathrm{Co}_{y} \mathrm{Fe}_{1-y}(\mathrm{OH})_{x}$ NSAs shown in Fig. 3 and S5-S7. $\dagger$ Spectra of Co $2 \mathrm{p}$ were split into $2 \mathrm{p}_{3 / 2}$ and $2 \mathrm{p}_{1 / 2}$ doublets due to spin-orbit coupling. Peak fitting analysis identified two Co states, with the characteristic peaks at binding energies of 797.4 and $781.5 \mathrm{eV}$ identified as $\mathrm{Co}^{2+}$, while the other two peaks at 796.1 and $780.5 \mathrm{eV}$ are assigned to $\mathrm{Co}^{3+} \cdot{ }^{39,40}$ Peak fitting analysis of the Co $2 \mathrm{p}$ spectra for the other $\mathrm{Co}-\mathrm{Fe}$ bimetal NSAs hydroxides produced similar results to those of the $\mathrm{Co}_{0.70} \mathrm{Fe}_{0.30}(\mathrm{OH})_{x}$ NSAs. Without Fe doping, the main peaks of Co $2 \mathrm{p}_{3 / 2}$ and Co $2 \mathrm{p}_{1 / 2}$ were at higher energy regions and only one chemical state of Co $\left(\mathrm{Co}^{2+}\right.$ at 782.2 and $\left.797.8 \mathrm{eV}\right)$ was detected. This can therefore be considered to be a $\mathrm{Co}(\mathrm{OH})_{2}$ NSAs structure. Additional evidence for the existence of $\mathrm{Co}^{2+}$ is provided by the satellite peaks (803.3 and $786.9 \mathrm{eV}$ ). The fact that the main Co $2 \mathrm{p}$ peak shifts to a higher energy with increased Fe doping implies that the oxidation of $\mathrm{Co}^{2+}$ is facilitated by the introduction of Fe. ${ }^{41}$ Peak fitting analyses of the Fe 2p spectra for the four bimetal NSAs hydroxides identified only one chemical state of $\mathrm{Fe}$, i.e., $\mathrm{Fe}^{3+}$ at 724.6 and $711.9 \mathrm{eV}^{\mathbf{4 2 , 4 3}}$ The peak in the Fe 2p spectra of Fe NSAs hydroxides are blue-shifted by about $0.6 \mathrm{eV}$ relative to those of Co-Fe bimetal NSAs hydroxides, which suggests that the pure Fe NSAs prepared using the same protocol are oxide rather than hydroxide. ${ }^{44}$ These results confirm that strong electron interactions involving $\mathrm{Fe}$ and Co occur in the $\mathrm{Co}_{y} \mathrm{Fe}_{1-y}(\mathrm{OH})_{x}$ NSAs. The $\mathrm{O}$ 1s spectra of the $\mathrm{Co}_{y} \mathrm{Fe}_{1-y}(\mathrm{OH})_{x}$ NSAs could be fitted with two peaks at binding energies of 530.6 and $531.6 \mathrm{eV}$, which prove the presence of lattice oxygen and hydroxide oxygen,

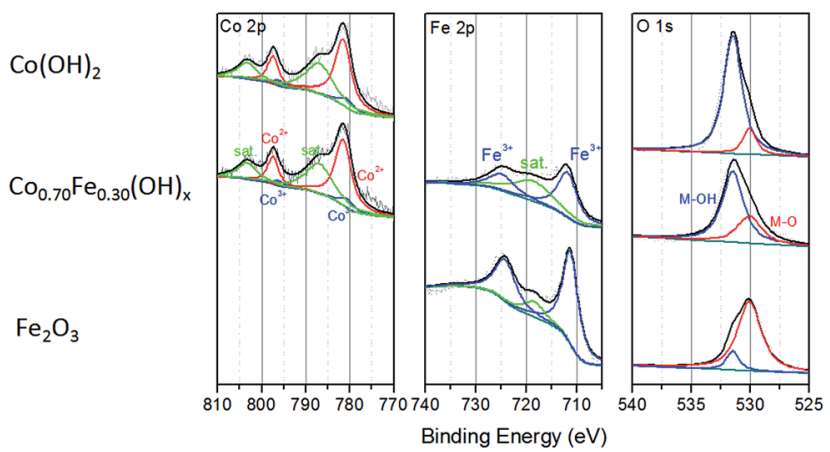

Fig. 3 High-resolution XPS spectra of $\mathrm{Co}(\mathrm{OH})_{2}, \mathrm{CO}_{0.70} \mathrm{Fe}_{0.30}(\mathrm{OH})_{x^{\prime}}$ and $\mathrm{Fe}_{2} \mathrm{O}_{3}$ NSAs. respectively. ${ }^{45,46}$ The $\mathrm{O}$ 1s spectra shifted to a lower binding energy following the addition of $\mathrm{Fe}$, which indicates that $\mathrm{O}$ was in a more oxide-like environment due to the partial conversion of $\mathrm{Co} / \mathrm{Fe}(\mathrm{OH})_{x}$ to $\mathrm{Fe} / \mathrm{Co}$-oxide phases. ${ }^{28,47}$ The $\mathrm{O}$ 1s spectrum of the $\mathrm{Fe}(\mathrm{OH})_{x}$ NSAs shifted to $530.1 \mathrm{eV}$, thereby proving the dominance of oxide ions over oxygen atoms. Combined with the blue-shift of Fe 2p spectra, we can confirm that the $\mathrm{Fe}(\mathrm{OH})_{x}$ more likely to be $\mathrm{Fe}_{2} \mathrm{O}_{3}$. The status of the $\mathrm{Co}-\mathrm{Fe}$ based hydroxide can be verified by the decrease in strength in the $\mathrm{O}-\mathrm{H}$ stretching vibration peaks $\left(\approx 3297 \mathrm{~cm}^{-1}\right)$ and scissoring vibration peaks (1700-1500 $\mathrm{cm}^{-1}$ from water, $1400-1300 \mathrm{~cm}^{-1}$ from structure hydroxyl groups) with increasing Fe ratio that is evident in the infrared (IR) spectra of the samples (Fig. S8 $\dagger$ ), which is consistent with the XPS results. ${ }^{\mathbf{4 8 , 4 9}}$ The broadening of the M-O scissoring vibration peaks $\left(500-700 \mathrm{~cm}^{-1}\right)$ with increasing $\mathrm{Fe}$ doping indicate an increase of $\mathrm{Fe}-\mathrm{O}$.

The electrocatalytic performance of the $\mathrm{Co}_{y} \mathrm{Fe}_{1-y}(\mathrm{OH})_{x}$ NSAs with different ratios of $\mathrm{Co}$ and $\mathrm{Fe}$ was investigated by linear sweep voltammetry (LSV) between 1.3 and $1.65 \mathrm{~V}$ (versus RHE) in $1 \mathrm{M} \mathrm{KOH}$ using a three-electrode system (Fig. 4a). The $\mathrm{Cu}_{2} \mathrm{O}$ nanoarrays on $\mathrm{Cu}$ foam show negligible activity, as these were simply used as a sacrificial template for the $\mathrm{Co}_{y} \mathrm{Fe}_{1-y}(\mathrm{OH})_{x}$ NSAs. In contrast, the $\mathrm{Co}_{0.70} \mathrm{Fe}_{0.30}(\mathrm{OH})_{x}$ and $\mathrm{Co}_{0.55} \mathrm{Fe}_{0.45}(\mathrm{OH})_{x}$ NSAs exhibit a sharp onset potential that is indicative of OER current at $1.45 \mathrm{~V} v s$. RHE, with a small overpotential $(\eta, \eta=E-$ $1230 \mathrm{mV})^{50}$ of $220 \mathrm{mV}$. The other two hybrid samples (i.e., the $\mathrm{Co}_{0.75} \mathrm{Fe}_{0.25}(\mathrm{OH})_{x}$ and $\mathrm{Co}_{0.41} \mathrm{Fe}_{0.59}(\mathrm{OH})_{x}$ NSAs) also exhibit high performance, with a slightly positive-shift onset $\eta$. Remarkably, all of the samples possess lower onset $\eta$ values than singlemetal catalysts. The $\mathrm{Co}_{0.70} \mathrm{Fe}_{0.30}(\mathrm{OH})_{x}$ NSAs also exhibit a markedly faster increase in anodic current density when compared to the other samples. In addition to the onset potential, the $\eta$ required for a current density of $10 \mathrm{~mA} \mathrm{~cm}{ }^{-2}$ is also commonly used as a criterion for evaluating the OER activity, and this can be seen to exhibit a similar trend. It is interesting that the as-made $\mathrm{Co}_{0.70} \mathrm{Fe}_{0.30}(\mathrm{OH})_{x}$ NSAs shows
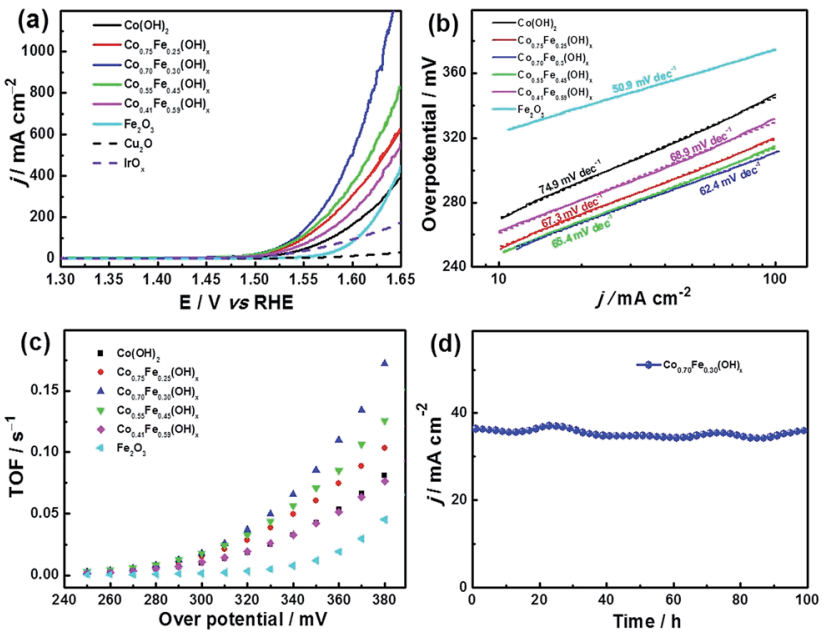

Fig. 4 (a) Polarization LSV curves of $\mathrm{CO}_{y} \mathrm{Fe}_{1-y}(\mathrm{OH})_{x}$ NSAs, $\mathrm{Cu}_{2} \mathrm{O}$ nanoarrays and $\mathrm{IrO}_{x}$ ( (b) Tafel and (c) TOF plots of $\mathrm{Co}_{y} \mathrm{Fe}_{1-y}(\mathrm{OH})_{x} \mathrm{NSAs}$; (d) chronoamperometric measurements $(\eta=300 \mathrm{mV})$ of $\mathrm{Co}_{0.70^{-}}$ $\mathrm{Fe}_{0.30}(\mathrm{OH})_{x} \mathrm{NSAs}$. 
a dramatically increased peak current density and reduce of $\eta$ in comparison to that of the $\mathrm{Co}(\mathrm{OH})_{2}$ NSAs, which mainly attributed to the synergistic effects between Co and Fe species in the hydroxide structure. ${ }^{27}$ In addition to providing excellent performance under typical OER testing conditions, the $\mathrm{Co}_{0.70^{-}}$ $\mathrm{Fe}_{0.30}(\mathrm{OH})_{x}$ NSAs provide a useable working ability under much more stringent conditions, which allows a large amount of highperformance active catalyst to be directly grown on its surface. This results in a current density as high as $1200 \mathrm{~mA} \mathrm{~cm}^{-2}$ at a $\eta$ as low as $410 \mathrm{mV}$ (Fig. 4a). The wavy line on the high potential part of $\mathrm{Co}_{0.70} \mathrm{Fe}_{0.30}(\mathrm{OH})_{x}$ NSAs owing to the violent release of gas bubbles. The electron conductivity between the collector and active catalyst is also more favourable than in a traditional nanoparticle-cast electrode. Moreover, as shown in Fig. 4b, the improved reaction kinetics of $\mathrm{Co}_{0.70} \mathrm{Fe}_{0.30}(\mathrm{OH})_{x}$ NSAs is reflected

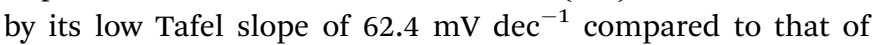
$\mathrm{Co}(\mathrm{OH})_{2}\left(74.9 \mathrm{mV} \mathrm{dec}{ }^{-1}\right), \mathrm{Co}_{0.75} \mathrm{Fe}_{0.25}(\mathrm{OH})_{x}\left(67.3 \mathrm{mV} \mathrm{dec}{ }^{-1}\right)$, $\mathrm{Co}_{0.55} \mathrm{Fe}_{0.45}(\mathrm{OH})_{x} \quad\left(65.4 \mathrm{mV} \quad \mathrm{dec}^{-1}\right)$ and $\mathrm{Co}_{0.41} \mathrm{Fe}_{0.59}(\mathrm{OH})_{x}$ (68.9 $\mathrm{mV} \mathrm{dec}^{-1}$ ) NSAs. It is worth noticing that $\mathrm{Fe}_{2} \mathrm{O}_{3}$ NSAs possess a much lower Tafel slope of $50.9 \mathrm{mV} \mathrm{dec}^{-1}$ and a positive onset $\eta$ of $270 \mathrm{mV}$, which suggests more favourable kinetics yet poor thermodynamics. This is because Fe catalyst only has measurable conductivity at $\eta$ larger than $400 \mathrm{mV}$, therefore, its outstanding kinetics property only show in high $\eta$ regions. $^{28}$ However, the addition of Co efficiently enhance the electrical conductive and result in enhanced OER activity. Therefore, doping of Fe is a sufficient solution to eliminate the kinetically slow of OER.

The improvement in OER activity can be quantified by the turnover frequency (TOF), which is defined as the number of moles of $\mathrm{O}_{2}$ per mole of metal catalyst per second. If it is assumed that all metal ions (Co and $\mathrm{Fe}$ ) in the hydroxide NSAs are available for OER, then an apparent TOF value can be calculated at different values of $\eta$. As shown in Fig. 4c, the TOF of the $\mathrm{Co}_{0.70} \mathrm{Fe}_{0.30}(\mathrm{OH})_{x}$ NSAs increases at a markedly faster rate than the other samples; and so not surprisingly, produces a higher TOF $\left(0.172 \mathrm{~s}^{-1}\right)$ than $\mathrm{Co}_{0.75} \mathrm{Fe}_{0.25}(\mathrm{OH})_{x} \operatorname{NSAs}\left(0.103 \mathrm{~s}^{-1}\right)$ and $\mathrm{Co}_{0.55} \mathrm{Fe}_{0.45}(\mathrm{OH})_{x}$ NSAs $\left(0.126 \mathrm{~s}^{-1}\right)$ at a working potential of $380 \mathrm{mV}$. This TOF is also much higher than that achieved with the non-doped NSAs, i.e., $\mathrm{Co}(\mathrm{OH})_{2}$ NSAs $\left(0.081 \mathrm{~s}^{-1}\right)$ and $\mathrm{Fe}_{2} \mathrm{O}_{3}$ NSAs $\left(0.045 \mathrm{~s}^{-1}\right)$. The OER performance of the $\mathrm{Co}_{y} \mathrm{Fe}_{1-y}(\mathrm{OH})_{x}$ NSAs is summarized in Table $\mathrm{S} 2, \uparrow$ from which we see that the critical values of $\mathrm{Co}_{0.70} \mathrm{Fe}_{0.30}(\mathrm{OH})_{x}$ NSAs are comparable to the state-of-the-art materials for OER catalysts (Table S4†). The durability of the electrode was evaluated by means of the chronoamperometry method. In Fig. $4 \mathrm{~d}$, the as-prepared $\mathrm{Co}_{0.70} \mathrm{Fe}_{0.30}(\mathrm{OH})_{x}$ NSAs electrode clearly exhibits greater stability, with no obvious decline in current density after $100 \mathrm{~h}$. This remarkable operational stability can be ascribed to the excellent intrinsic stability and enhanced activity of the $\mathrm{Co}_{0.70^{-}}$ $\mathrm{Fe}_{0.30}(\mathrm{OH})_{x}$ catalyst, as well as the sturdiness of the entire electrode and reduced coverage of gas bubbles. ${ }^{51}$

The electrode kinetics were further analyzed by simulating the charge transfer resistance obtained through electrochemical impedance spectroscopy (EIS) during oxygen evolution $(\eta=300 \mathrm{mV})$ in a solution of $1.0 \mathrm{M} \mathrm{KOH} \mathrm{(Fig.} \mathrm{5).} \mathrm{The}$ Zsimpwin 3.5 was used to fit the resistance values, and the

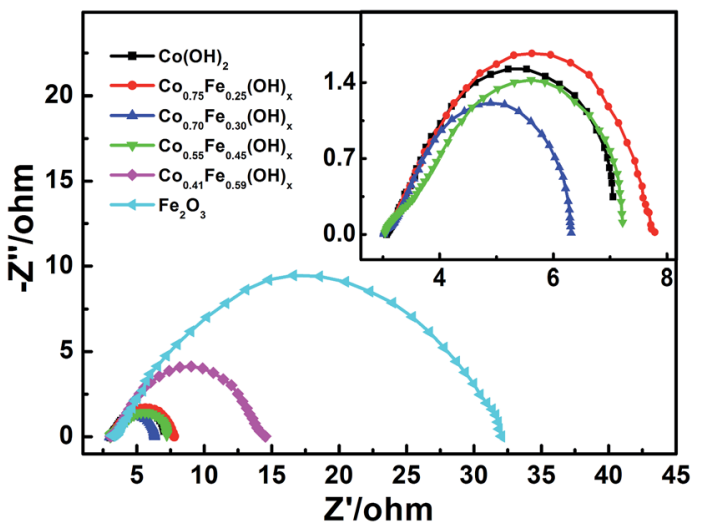

Fig. 5 Nyquist plots of $\mathrm{Co}_{y} \mathrm{Fe}_{1-y}(\mathrm{OH})_{x} \mathrm{NSAs}$, the insert is magnification Nyquist plots of $\mathrm{Co}(\mathrm{OH})_{2}, \mathrm{Co}_{0.75} \mathrm{Fe}_{0.25}(\mathrm{OH})_{x}, \mathrm{Co}_{0.70} \mathrm{Fe}_{0.30}(\mathrm{OH})_{x}$ and $\mathrm{Co}_{0.55} \mathrm{Fe}_{0.45}(\mathrm{OH})_{x} \mathrm{NSAs}$.

results obtained are shown in Table S3. $\dagger$ As illustrated in Fig. $S 9, \dagger$ the equivalent circuit consists of three main parts: the solution resistance $R_{\mathrm{s}}$, the charge transfers resistance $R_{\mathrm{ct}}$ and the constant phase resistance $R_{\mathrm{cp}}$. The $R_{\mathrm{ct}}$ of the six electrodes was in the order of $\mathrm{Co}_{0.70} \mathrm{Fe}_{0.30}(\mathrm{OH})_{x}<\mathrm{Co}_{0.55} \mathrm{Fe}_{0.45}(\mathrm{OH})_{x}<$ $\mathrm{Co}(\mathrm{OH})_{2}<\mathrm{Co}_{0.25} \mathrm{Fe}_{0.75}(\mathrm{OH})_{x}<\mathrm{Co}_{0.41} \mathrm{Fe}_{0.59}(\mathrm{OH})_{x}<\mathrm{Fe}_{2} \mathrm{O}_{3}$ NSAs, indicating a marked increase in $R_{\mathrm{ct}}$ with increasing Fe content, especially at $>40$ at $\% \mathrm{Fe}^{52} \mathrm{~A}$ much smaller $R_{\mathrm{ct}}$ suggesting a much faster electron transfer and a higher faradaic efficiency during reaction. ${ }^{53,54}$ Therefore, good conductivity and faster reaction speed of materials can improve the charge transfer kinetics. The $\mathrm{Co}(\mathrm{OH})_{2}$ NSAs possess a small $R_{\mathrm{ct}}$, yet only provide a relatively unromantic electrocatalytic activity on account of the inherent electrical conductivity and inferior activity of Co hydroxide compared to Co-Fe hydroxide. This again proves that $\mathrm{Co}_{0.70} \mathrm{Fe}_{0.30}(\mathrm{OH})_{x}$ NSAs provides the appropriate conductivity and good electrocatalytic activity and bring about optimal performance for OER. These results consistent with the kinetics results of Tafel plots, which further prove the electronic interaction between Fe and Co in the hydroxides. Similar optimal of Co to Fe ratios being found in previous studies: e.g., CoFe-LDH with a Co to Fe ratio of $3: 1$ has a greater OER activity than $\mathrm{Co}(\mathrm{OH})_{2}$ and mixed-phase samples of $\mathrm{Co}(\mathrm{OH})_{2}$ and $\mathrm{FeOOH}^{27}$ The intrinsic OER activity of $\mathrm{Co}_{1-x} \mathrm{Fe}_{x}(\mathrm{OOH})$ is also known to be $\sim 100$-fold higher when $x \approx 0.6-0.7$ than when $x=0$ on a permetal TOF basis. ${ }^{28}$

Based on the SEM and TEM results, it would seem that CoFe based NSAs expose more surface area than $\mathrm{Co}(\mathrm{OH})_{2}$ NSAs. To confirm this hypothesis, type-IV nitrogen adsorptiondesorption isotherms were obtained for the $\mathrm{Co}_{0.70} \mathrm{Fe}_{0.30}(\mathrm{OH})_{x}$ NSAs and $\mathrm{Co}(\mathrm{OH})_{2}$ NSAs, as this provides an indication of the mesoporous nature of the nanosheet (Fig. 6a). A H3-type hysteresis loop was also identified in the isotherms, which provides further evidence of nanosheet aggregation. ${ }^{55}$ The BET surface area of $\mathrm{Co}_{0.70} \mathrm{Fe}_{0.30}(\mathrm{OH})_{x}$ NSAs was much higher than that of $\mathrm{Co}(\mathrm{OH})_{2}$ NSAs (89 vs. $67 \mathrm{~m}^{2} \mathrm{~g}^{-1}$ ), which is consistent with the electrochemical surface area (ECSA) of $\mathrm{Co}_{0.70} \mathrm{Fe}_{0.30}(-$ $\mathrm{OH})_{x}\left(105 \mathrm{~cm}^{2}\right)$ and $\mathrm{Co}(\mathrm{OH})_{2}\left(75 \mathrm{~cm}^{2}\right)$ NSAs calculate by doublelayer capacitance (Fig. S10 $\dagger$ ). However, as the structural 

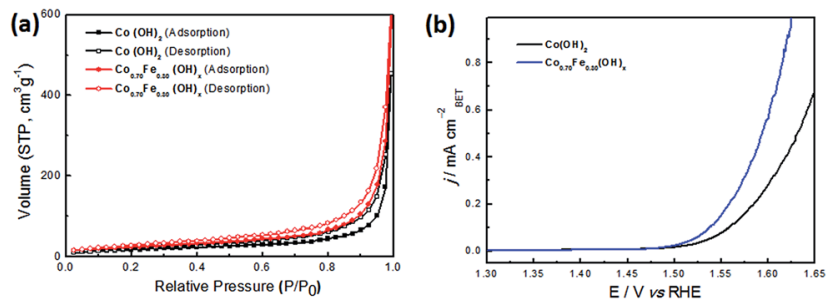

Fig. 6 (a) Nitrogen adsorption-desorption isotherms and (b) polarization LSV curves normalized to the BET surface area of $\mathrm{Co}(\mathrm{OH})_{2}$ and $\mathrm{Co}_{0.70} \mathrm{Fe}_{0.30}(\mathrm{OH})_{x} \mathrm{NSAs}$.

disorder in these amorphous materials may create more defect sites capable of serving as efficient reaction centers, ${ }^{56,57}$ the specific activity (current per BET area) was used to specify the density of active sites. Fig. 6b shows the LSV curves after normalizing the current to the BET surface area. It is evident from this that the specific activity of $\mathrm{Co}_{0.70} \mathrm{Fe}_{0.30}(\mathrm{OH})_{x}$ was 0.37 $\mathrm{mA} \mathrm{cm}{ }_{\mathrm{BET}}{ }^{-2}$ at a $\eta$ value of $350 \mathrm{mV}$, which is twice as high as that of $\mathrm{Co}(\mathrm{OH})_{2}$ NSAs $\left(0.19 \mathrm{~mA} \mathrm{~cm}_{\mathrm{BET}}{ }^{-2}\right)$. This confirms that Fe doping contributes to creating more active sites, and as the performance of a catalyst is strongly influenced by its geometric roughness, ${ }^{34,58}$ the excellent activity of $\mathrm{Co}_{0.70} \mathrm{Fe}_{0.30}(-$ $\mathrm{OH})_{x}$ can be attributed to its high surface area and greater number of active sites. Previous studies have also demonstrated that the large surface area of ultrathin nanosheet array is beneficial to the mass transfer and utilization of catalysts, as well as providing a sturdy and close-knit current collector that effectively reduces the size of any gas bubbles and their associated adverse effects. ${ }^{51}$

The above results clearly demonstrate that compared with $\mathrm{Co}(\mathrm{OH})_{2}$ NSAs, the introduction of Fe significantly improves the catalytic activity. Firstly, hybrid Co-Fe hydroxides (or oxides) are well-known excellent active materials with high activity and stability in OER applications. ${ }^{28}$ The low Tafel slope and $R_{\mathrm{ct}}$ of $\mathrm{Co}_{0.70} \mathrm{Fe}_{0.30}(\mathrm{OH})_{x}$ NSAs indicate an improved charge transfer kinetic, indicating doping of $\mathrm{Fe}$ is a sufficient solution to eliminate the kinetically slow of OER. The specific activity of $\mathrm{Co}_{0.7} \mathrm{Fe}_{0.3}(\mathrm{OH})_{x}$ NSAs at an overpotential of $350 \mathrm{mV}(0.37 \mathrm{~mA}$ $\mathrm{cm}_{\text {BET }}{ }^{-2}$ ) is twice as high as that of undoped $\mathrm{Co}(\mathrm{OH})_{2}$ NSAs, further prove the positive effect of Fe doping on OER activity. Secondly, nanoarray structures with high specific surface area not only provide large reaction interface but also ensure efficient charge conductivity, which is benefit for utilization in areas of electrochemical catalyst. The BET surface area of $\mathrm{Co}_{0.70} \mathrm{Fe}_{0.30}(\mathrm{OH})_{x}$ NSAs was much higher than that of $\mathrm{Co}(\mathrm{OH})_{2}$ NSAs (89vs. $67 \mathrm{~m}^{2} \mathrm{~g}^{-1}$ ). The empty space between nanoarrays would facilitate the transfer of the electrolyte thus benefit the charge transfer kinetic. Thirdly, integrated electrode can provide good conductivity and sturdiness electrode structure, bring about excellent stability, with no obvious decline in current density after $100 \mathrm{~h}$. Most of all, $\mathrm{Co}_{0.70} \mathrm{Fe}_{0.30}(\mathrm{OH})_{x}$ NSAs provide an optimum Fe-doping ratio, increased geometric roughness, more active sites and a sturdy electrode structure, all of which contribute to greater overall electrocatalytic performance.

\section{Conclusions}

This study has succeeded in synthesizing a series of hierarchical $\mathrm{Co}_{y} \mathrm{Fe}_{1-y}(\mathrm{OH})_{x}$ NSAs integrated on a three-dimensional electrode and shown that the Fe-doping helps to increase both the geometric roughness and density of active sites. Of all the samples tested, $\mathrm{Co}_{0.7} \mathrm{Fe}_{0.3}(\mathrm{OH})_{x}$ NSAs delivered the highest anodic current for OER at a low $\eta$, and exhibited excellent stability with no obvious decline in current density after $100 \mathrm{~h}$. This electrode also possessed a large surface area of $89 \mathrm{~m}^{2} \mathrm{~g}^{-1}$ and a specific activity of $0.37 \mathrm{~mA} \mathrm{~cm}_{\mathrm{BET}}{ }^{-2}$ at a $\eta$ value of $350 \mathrm{mV}$ that is twice as much as that of $\mathrm{Co}(\mathrm{OH})_{2}$ NSAs. The outstanding electrocatalytic performance of $\mathrm{Co}_{0.7} \mathrm{Fe}_{0.3}(\mathrm{OH})_{x}$ NSAs can be attributed to an optimization of the effects of Fe-doping and an open 3D electrode design. These results open a new avenue for the rational design and controllable preparation of hierarchical Co-Fe based nanoelectrodes capable of providing the high catalytic activity and excellent stability needed for clean energy technologies.

\section{Experimental}

\section{Materials}

Cobalt(II) dichloride $\left(\mathrm{CoCl}_{2} \cdot 6 \mathrm{H}_{2} \mathrm{O}, \mathrm{AR}\right)$, iron(II) dichloride $\left(\mathrm{FeCl}_{2} \cdot 4 \mathrm{H}_{2} \mathrm{O}, \mathrm{AR}\right)$, potassium hydroxide $(\mathrm{KOH}, \mathrm{AR})$, sodium hyposulfite $\left(\mathrm{Na}_{2} \mathrm{~S}_{2} \mathrm{O}_{3} \cdot 5 \mathrm{H}_{2} \mathrm{O}, \mathrm{AR}\right)$, oxalic acid $\left(\mathrm{H}_{2} \mathrm{C}_{2} \mathrm{O}_{4}, \mathrm{AR}\right)$, ethanol $\left(\mathrm{CH}_{3} \mathrm{CH}_{2} \mathrm{OH}, \mathrm{AR}\right)$ were purchased from Sinopharm Chemical Reagent Co., Ltd. All chemicals were used as received without further purification. Milli-Q water (resistivity $>18 \mathrm{M} \Omega$ $\mathrm{cm}$ ) was used throughout the experiments.

\section{Synthesis of the $\mathrm{Co}_{y} \mathrm{Fe}_{1-y}(\mathrm{OH})_{x}$ NSAs}

Copper foam (100 pores per inch, $98 \%$ porosity, and $\sim 1.5 \mathrm{~mm}$ thick) was cut into squares $(2.0 \mathrm{~cm} \times 2.0 \mathrm{~cm})$ and cleaned with Milli-Q water and ethanol before use. It was then anodized in a $0.4 \mathrm{M} \mathrm{H}_{2} \mathrm{C}_{2} \mathrm{O}_{4}$ solution for $20 \mathrm{~min}$ at $36 \mathrm{~V}$ using a graphite plate as the cathode electrode. Electro-oxidation was then conducted using a potentiostat (760D, CHI Instruments) with a three-electrode system, wherein the anodized $\mathrm{Cu}$ foam was used as a working electrode, platinum wire as the counter electrode and an $\mathrm{Ag} / \mathrm{AgCl}$ electrode as the reference electrode. Cyclic voltammetry was performed over a potential range from -0.3 to $0.1 \mathrm{~V}$ at a scanning rate of $1 \mathrm{mV} \mathrm{s}^{-1}$ in a $1 \mathrm{M} \mathrm{KOH}$ aqueous solution to accomplish the in situ growth of $\mathrm{Cu}_{2} \mathrm{O}$ nanowire arrays on the surface of the $\mathrm{Cu}$ foam..$^{35}$ These $\mathrm{Cu}_{2} \mathrm{O}$ nanowire arrays were subsequently sacrificed to fabricate $\mathrm{Co}_{y^{-}}$ $\mathrm{Fe}_{1-y}(\mathrm{OH})_{x} \mathrm{NSAs}^{36}$ by first dissolving set amounts of $\mathrm{CoCl}_{2}-$ $\cdot 6 \mathrm{H}_{2} \mathrm{O}$ and $\mathrm{FeCl}_{2} \cdot 4 \mathrm{H}_{2} \mathrm{O}$ in a mixed solution of $17.5 \mathrm{~mL}$ Milli-Q water and $17.5 \mathrm{~mL}$ ethanol to give a molar ratios of $\mathrm{CoCl}_{2}$ $\cdot 6 \mathrm{H}_{2} \mathrm{O}$ to $\mathrm{FeCl}_{2} \cdot 4 \mathrm{H}_{2} \mathrm{O}$ of $1: 0,3: 1,2: 1,1: 1,1: 2$ and $0: 1$. The total amount of $\mathrm{CoCl}_{2} \cdot 6 \mathrm{H}_{2} \mathrm{O}$ and $\mathrm{FeCl}_{2} \cdot 4 \mathrm{H}_{2} \mathrm{O}$ was $8 \times$ $10^{-5}$ mol. The samples of $\mathrm{Cu}$ foam decorated with $\mathrm{Cu}_{2} \mathrm{O}$ nanowire arrays were immersed into one of the above suspensions, and then $10 \mathrm{~mL}$ of $\mathrm{Na}_{2} \mathrm{~S}_{2} \mathrm{O}_{3}(1 \mathrm{M})$ solution was added dropwise with magnetic stirring for $1 \mathrm{~h}$. Finally, the substrate was taken out and washed in ethanol and Mill-Q water several times, followed by drying at $60{ }^{\circ} \mathrm{C}$ in a vacuum oven for $4 \mathrm{~h}$. 


\section{Material characterizations}

Scanning electron microscopy (SEM) was performed using a ZEISS MERLIN and microstructure investigations were carried out using a JEOL JEM-2100 at $200 \mathrm{kV}$. Element mappings were obtained with a FEI Tecnai $\mathrm{G}^{2} \mathrm{~F} 2 \mathrm{O}$ operating at $200 \mathrm{kV}$, while Xray diffraction (XRD) patterns were recorded using a Rigaku Ultima IV. The chemical valence state of the elements was determined by X-ray photoelectron spectroscopy (XPS, PHI 5000 VersaProbe), with all spectra being corrected by the $\mathrm{C} 1 \mathrm{~s}$ binding energy of $284.8 \mathrm{eV}$. The genuine atomic ratios of Co to $\mathrm{Fe}$ were evaluated by inductively coupled plasma (ICP) emission spectrometry (VISTA-MPX). Brunauer-Emmett-Teller (BET) measurements were performed on a Quadrasorb SI analyzer at $77 \mathrm{~K}$.

\section{Electrochemical measurements}

Electrochemical measurements were performed in an $\mathrm{O}_{2}$-saturated $1 \mathrm{M} \mathrm{KOH}$ electrolyte with an electrochemical analyzer (CHI 760D Instruments) and a three-electrode system that consisted of $\mathrm{Hg} / \mathrm{HgO}(1 \mathrm{M} \mathrm{KOH})$ with a double salt bridge as a reference electrode, platinum wire as a counter electrode, and the $\mathrm{Co}_{y} \mathrm{Fe}_{1-y}(\mathrm{OH})_{x}$ NSAs $(0.5 \mathrm{~cm} \times 0.5 \mathrm{~cm})$ on $\mathrm{Cu}$ foam as the working electrode. The $\mathrm{Hg} / \mathrm{HgO}$ electrode was calibrated against a reversible hydrogen electrode (RHE) in a $1 \mathrm{M} \mathrm{KOH}$ solution (see Fig. S11 $\dagger$ ) that was bubbled with hydrogen for 30 min prior to calibration to ensure it was saturated with hydrogen. Two platinum wires were used as the working electrode and counter electrode. Cyclic voltammetry (CV) curves were recorded at a scan rate of $2 \mathrm{mV} \mathrm{s}^{-1}$ and the average of the positive and negative potentials at which the current crossed zero was taken to be the thermodynamic potential for the hydrogen electrode reaction. All polarization measurements were performed at a scanning rate of $5 \mathrm{mV} \mathrm{s}^{-1}$, from which the potentials were calculated relative to the (RHE) according to the following equation: $E(\mathrm{RHE})=E(\mathrm{Hg} / \mathrm{HgO})+0.098+0.0591 \times$ $\mathrm{pH}$. The calibrated potential of the $\mathrm{Hg} / \mathrm{HgO}(0.9 \mathrm{~V} v s$. RHE) was found to be consistent with the calculated result $(0.896 \mathrm{~V} v s$. RHE). The durability was assessed using the controlled potential electrolysis method, in which all of the cyclic electrochemical measurements are $75 \%$ iR-compensated. Electrochemical impedance spectroscopy was performed over a frequency range of $10^{-2}$ to $10^{4} \mathrm{~Hz}$ with an amplitude of $5 \mathrm{mV}$ at the Princeton PMC 1000 electrochemical workstation. All electrochemical tests were carried out at $25^{\circ} \mathrm{C}$.

The TOF values were calculated from the followed equation:

$$
\mathrm{TOF}=(j \times a) /(4 \times n \times F) .
$$

Where $j$ is the measured current density at a given potential, $a$ is the surface area of the electrode $\left(0.25 \mathrm{~cm}^{2}\right), 4$ is the electron transfer number during $\mathrm{O}_{2}$ production, $n$ is the number of metal ions (including Co and Fe) on the electrode in moles, and $F$ is the Faraday constant $\left(F=96485 \mathrm{C} \mathrm{mol}^{-1}\right)$.

The electrochemically active surface area (ECSA) was estimated by the double-layer capacitance at a potential range (0.896-0.946 V vs. RHE) with no faradaic current from cyclic voltammetry (CV). The electrochemical double-layer capacitance $\left(C_{\mathrm{DL}}\right)$ was measured by scan-rate dependent CVs, as given by the followed equation:

$$
i=v C_{\mathrm{DL}}
$$

a plot of current $(i)$ as a function of $v$ yields a straight line with a slope equal to $C_{\mathrm{DL}}$ (Fig. S10†).

The ECSA was calculated according to the followed equation:

$$
\mathrm{ECSA}=C_{\mathrm{DL}} / C_{\mathrm{s}}
$$

where $C_{\mathrm{s}}$ is the specific capacitance of an atomically smooth planar surface of material per unit area under identical electrolyte conditions, we use $C_{\mathrm{s}}=0.040 \mathrm{mF} \mathrm{cm}^{-2}$ in $1 \mathrm{M} \mathrm{KOH}$ based on typical reported values.

\section{Acknowledgements}

This work was financially supported by the National 973 Program Project of China (2012CB932800), National Natural Science Foundation of China (51572016, 21402136), Natural Science Foundation of Tianjin City (16JCYBJC17000), and the Specialized Research Fund for the Doctoral Program of Higher Education of China (20133201120004). YFZ thank the support provided by the "Talent Program" of Tianjin University of Technology. YFZ thanks the financial support received from the "Youth Thousand Talents Program" of Tianjin City.

\section{Notes and references}

1 M. R. Shaner, S. Hu, K. Sun and N. S. Lewis, Energy Environ. Sci., 2015, 8, 203-207.

2 X. Lang, L. Zhang, T. Fujita, Y. Ding and M. Chen, J. Power Sources, 2012, 197, 325-329.

3 B. Li, M. Zheng, H. Xue and H. Pang, Inorg. Chem. Front., 2016, 3, 175-202.

4 W. Yu, X. Jiang, F. Meng, Z. Zhang, H. Ma and X. Liu, RSC Adv., 2016, 6, 34501-34506.

5 Y. Jiao, Y. Zheng, M. Jaroniec and S. Z. Qiao, Chem. Soc. Rev., 2015, 44, 2060-2086.

6 J. Ren, M. Antonietti and T.-P. Fellinger, Adv. Energy Mater., 2015, 5, 1401660.

7 Y. Lee, J. Suntivich, K. J. May, E. E. Perry and Y. Shao-Horn, J. Phys. Chem. Lett., 2012, 3, 399-404.

8 D. Chen, C. Chen, Z. M. Baiyee, Z. Shao and F. Ciucci, Chem. Rev., 2015, 115, 9869-9921.

9 J. Jiang, A. Zhang, L. Li and L. Ai, J. Power Sources, 2015, 278, 445-451.

10 H. Yin and Z. Tang, Chem. Soc. Rev., 2016, 45, 48734891.

11 X. Yu, M. Zhang, W. Yuan and G. Shi, J. Mater. Chem. A, 2015, 3, 6921-6928.

12 F. Dionigi and P. Strasser, Adv. Energy Mater., 2016, 1600621.

13 G. B. B. Varadwaj and V. O. Nyamori, Nano Res., 2016, 9, 3598-3621. 
14 A. Bergmann, E. Martinez-Moreno, D. Teschner, P. Chernev, M. Gliech, J. F. de Araujo, T. Reier, H. Dau and P. Strasser, Nat. Commun., 2015, 6, 8625.

15 X. Li, G. Guan, X. Du, A. D. Jagadale, J. Cao, X. Hao, X. Ma and A. Abudula, RSC Adv., 2015, 5, 76026-76031.

16 K. He, Z. Cao, R. Liu, Y. Miao, H. Ma and Y. Ding, Nano Res., 2016, 9, 1856-1865.

17 J. Nai, H. Yin, T. You, L. Zheng, J. Zhang, P. Wang, Z. Jin, Y. Tian, J. Liu, Z. Tang and L. Guo, Adv. Energy Mater., 2015, 5, 1401880.

18 M. Gong and H. Dai, Nano Res., 2015, 8, 23-39.

19 J. Suntivich, K. J. May, H. A. Gasteiger, J. B. Goodenough and Y. Shao-Horn, Science, 2011, 334, 1383-1385.

20 M. Wei, M. Renzhi, W. Chengxiang, L. Jianbo, L. Xiaohe, Z. Kechao and T. Sasaki, ACS Nano, 2015, 9, 1977-1984.

21 Z. Lu, W. Xu, W. Zhu, Q. Yang, X. Lei, J. Liu, Y. Li, X. Sun and X. Duan, Chem. Commun., 2014, 50, 6479-6482.

22 M. Gong, Y. Li, H. Wang, Y. Liang, J. Z. Wu, J. Zhou, J. Wang, T. Regier, F. Wei and H. Dai, J. Am. Chem. Soc., 2013, 135, 8452-8455.

23 J. Luo, J. H. Im, M. T. Mayer, M. Schreier, M. K. Nazeeruddin, N. G. Park, S. D. Tilley, H. J. Fan and M. Gratzel, Science, 2014, 345, 1593-1596.

24 T. Grewe, X. Deng and H. Tüysüz, Chem. Mater., 2014, 26, 3162-3168.

25 M. S. Burke, M. G. Kast, L. Trotochaud, A. M. Smith and S. W. Boettcher, J. Am. Chem. Soc., 2015, 137, 3638-3648.

26 G. Abellán, J. A. Carrasco, E. Coronado, J. Romero and M. Varela, J. Mater. Chem. C, 2014, 2, 3723-3731.

27 X. Han, C. Yu, J. Yang, C. Zhao, H. Huang, Z. Liu, P. M. Ajayan and J. Qiu, Adv. Mater. Interfaces, 2016, 3, 15000782.

28 M. S. Burke, M. G. Kast, L. Trotochaud, A. M. Smith and S. W. Boettcher, J. Am. Chem. Soc., 2015, 137, 3638-3648.

29 J. X. Feng, H. Xu, Y. T. Dong, S. H. Ye, Y. X. Tong and G. R. Li, Angew. Chem., Int. Ed., 2016, 55, 3694-3698.

30 X. Liu, Z. Chang, L. Luo, T. Xu, X. Lei, J. Liu and X. Sun, Chem. Mater., 2014, 26, 1889-1895.

31 H.-Y. Wang, Y.-Y. Hsu, R. Chen, T.-S. Chan, H. M. Chen and B. Liu, Adv. Energy Mater., 2015, 5, 1500091.

32 T. Tian, L. Ai and J. Jiang, RSC Adv., 2015, 5, 10290-10295.

33 P. Chen, K. Xu, Z. Fang, Y. Tong, J. Wu, X. Lu, X. Peng, H. Ding, C. Wu and Y. Xie, Angew. Chem., Int. Ed., 2015, 54, 14710-14714.

34 R. Chen, H.-Y. Wang, J. Miao, H. Yang and B. Liu, Nano Energy, 2015, 11, 333-340.

35 C. Dong, Y. Wang, J. Xu, G. Cheng, W. Yang, T. Kou, Z. Zhang and Y. Ding, J. Mater. Chem. A, 2014, 2, 18229-18235.

36 J. Nai, Y. Tian, X. Guan and L. Guo, J. Am. Chem. Soc., 2013, 135, 16082-16091.
37 J. Xie and Y. Xie, ChemCatChem, 2015, 7, 2568-2580.

38 S. Li, Y. Wang, S. Peng, L. Zhang, A. M. Al-Enizi, H. Zhang, X. Sun and G. Zheng, Adv. Energy Mater., 2016, 6, 1501661.

39 M. C. Biesinger, B. P. Payne, A. P. Grosvenor, L. W. M. Lau, A. R. Gerson and R. S. C. Smart, Appl. Surf. Sci., 2011, 257, 2717-2730.

40 Q. Zhang, H. Chen, X. Han, J. Cai, Y. Yang, M. Liu and K. Zhang, ChemSusChem, 2016, 9, 186-196.

41 R. Ma, J. Liang, K. Takada and T. Sasaki, J. Am. Chem. Soc., 2011, 133, 613-620.

42 B. M. Hunter, W. Hieringer, J. R. Winkler, H. B. Graya and A. M. Müller, Energy Environ. Sci., 2016, 9, 1734-1743.

43 S. Helmut, S. Shamaila, W. Lorenz, K. Karsten, D. Stephan, W. Joachim, S. Lilli, S. Martin, H. Jörg and D. Diemo, Energy Environ. Sci., 2015, 8, 2685-2697.

44 N. S. McIntyre and D. G. Zetaruk, Anal. Chem., 1977, 49, 1521-1529.

45 J. Masa, W. Xia, I. Sinev, A. Zhao, Z. Sun, S. Grutzke, P. Weide, M. Muhler and W. Schuhmann, Angew. Chem., Int. Ed., 2014, 53, 8508-8512.

46 T. Sun, L. Xu, Y. Yan, A. A. Zakhidov, R. H. Baughman and J. Chen, ACS Catal., 2016, 6, 1446-1450.

47 L. J. Enman, M. S. Burke, A. S. Batchellor and S. W. Boettcher, ACS Catal., 2016, 6, 2416-2423.

48 J. Qi, W. Zhang, R. Xiang, K. Liu, H.-Y. Wang, M. Chen, Y. Han and R. Cao, Adv. Sci., 2015, 2, 1500199.

49 Y. Qiu, L. Xin and W. Li, Langmuir, 2014, 30, 7893-7901.

50 I. C. Man, H.-Y. Su, C.-V. Federico, H. A. Hansen, J. I. Martínez, N. G. Inoglu, J. Kitchin, T. F. Jaramillo, J. K. Nørskov and J. Rossmeisl, ChemCatChem, 2011, 3, 1159-1165.

51 Z. Lu, Y. Li, X. Lei, J. Liu and X. Sun, Mater. Horiz., 2015, 2, 294-298.

52 S. Wang, J. Nai, S. Yang and L. Guo, ChemNanoMat, 2015, 1, 324-330.

53 X. Long, G. Li, Z. Wang, H. Zhu, T. Zhang, S. Xiao, W. Guo and S. Yang, J. Am. Chem. Soc., 2015, 137, 11900-11903.

54 Y. Li, L. Zhang, R. Liu, Z. Cao, X. Sun, X. Liu and J. Luo, ChemCatChem, 2016, 8, 2765-2770.

55 K. S. W. Sing and R. T. Williams, Adsorpt. Sci. Technol., 2004, 22, 773-782.

56 C. G. Morales-Guio and X. Hu, Acc. Chem. Res., 2014, 47, 2671-2681.

57 R. D. L. Smith, M. S. Prévot, R. D. Fagan, Z. Zhang, P. A. Sedach, M. K. J. Siu, S. Trudel and C. P. Berlinguette, Science, 2013, 340, 60-63.

58 M. Y. Song, D.-S. Yang, K. P. Singh, J. Yuan and J.-S. Yu, Appl. Catal., B, 2016, 191, 202-208. 